\title{
Family and Personal Predictors of Early Adolescent Eating Patterns
}

\author{
Stephen L Brown ${ }^{1}$, James Teufel ${ }^{2}$, Yuba R. Gautam ${ }^{1}$, Christie Norrick ${ }^{3} \&$ David Birch $^{4}$ \\ ${ }^{1}$ Southern Illinois University \\ ${ }^{2}$ OASIS Institute \\ ${ }^{3}$ Brown School Washington University \\ ${ }^{4}$ University of Alabama
}

\begin{abstract}
Many early adolescents report consuming less than the recommended five servings of fruits and vegetables a day, and up to one-third report skipping breakfast. Recent research suggests that children consider parents to be the gatekeepers of food choices, and that parents are important role models for children's eating behaviors. This study examined perceived control over food choices, familial communication regarding healthy eating, and preferred sources of information about healthy eating in relation to eating behaviors. Data were obtained from 959 early adolescents attending health programs in the Midwest. Early adolescents who reported more frequent family discussions were more likely to report eating two or more vegetables per day $(\mathrm{AOR}=1.4, \mathrm{p}<.05)$, three or more fruits per day $(\mathrm{AOR}=1.6, \mathrm{p}<.05)$, and five or more vegetables and/or fruits per day $(\mathrm{AOR}=1.9, \mathrm{p}<.05)$ than early adolescents who reported less family discussions. Those exposed to more frequent family discussions were also more likely to report usually eating breakfast $(\mathrm{AOR}=1.8, \mathrm{p}<.05)$. Older children were less likely to report eating breakfast (AOR $=0.2$ for ages 12 and13 compared to age 9, $\mathrm{p}<.05$ ). Although healthy eating behaviors decline with age, children and adolescents whose families reinforce healthy eating patterns appear more likely to maintain healthy patterns.
\end{abstract}

(c) 2012 Californian Journal of Health Promotion. All rights reserved.

Keywords:

\section{Introduction}

Adolescence is a time of rapid development that requires nutrient intake levels higher than adulthood (Larson, Neumark- Sztainer, Hannan, $\&$ Story, 2007) and behaviors developed during childhood and adolescence are typically carried over into adulthood (Nystrom, Schmitz, Perry, Lytle, \& Neumark-Sztainer, 2005; Woodruff \& Hanning, 2008; Fahlman, Dake, McCayghtry, \& Martin, 2008). According to the Youth Risk Behavior Surveillance Survey, less than one out of ten adolescents across the United States consumed at least two servings of fruit and at least three servings of vegetables per day (CDC, 2009). Healthy People 2010 (HP 2010) and HP 2020 include the goal of increasing the percentage of individuals ages two and older who consume at least two servings of fruit and at least three servings of vegetables daily.
Additionally, between $10 \%-30 \%$ of early adolescents skip breakfast on a given day and this proportion increases with age (Rampersaud, Pereira, Girard, Adams, \&, Metzl, 2005). Previous research suggests that adolescents who eat breakfast on a regular basis are more likely to have a lower body mass index and better academic performance compared to those who skip breakfast (Gleason \& Dodd, 2009).

Recent research suggests that early adolescents consider parents to be the gatekeepers of the family food supply, and also view their parents as role models and educators for their eating behaviors (Roseman, Yeung, \& Nickelsen, 2007; Benton, 2004; Wu, Snider, Floyd, Florence, Stoots, \& Makamey, 2009). While several studies detail eating patterns of early adolescents, this study examined, from the adolescents' perspective, from whom and where 
they obtain nutrition information . In addition to measuring breakfast, fruit and vegetable consumption, this study uniquely addresses the influence of perceived control over food choices, familial communication regarding healthy eating, and the preferred sources for information about healthy eating on early adolescent eating behaviors.

\section{Methods}

\section{Sample}

Data were obtained from 959 early adolescents ages nine to thirteen (early adolescents, popularly called "tweens"), attending programs at eight different National Association of Health Education Center locations. Half the respondents were boys and the average age was 10.3 years $(\mathrm{SD}=1.1)$. Health Education Centers, which are funded by private sources and visit fees, are similar to science centers, expect they have the primary goal of increasing health literacy in the young. Most centers allow walk-in visits by any member of the public, but also contract with many school districts to provide health education curricula. The centers involved in this study were located in Illinois, Indiana, Michigan, Pennsylvania, and Wisconsin.

Based on school-level data retrieved from the National Center of Educational Statistics (NCES, 2005), the schools participating in this study were similar to national averages: $66 \%$ white, 13\% Black, 16\% Hispanic, 5\% Asian/Pacific, and 1\% Native American. Thirtyseven percent of the early adolescents in participating schools qualified for free or reduced lunch. Regarding school locale, $21 \%$ of the schools were located within a large city center; $20 \%$ in a midsize city center area; $26 \%$ in a large city fringe area; and $33 \%$ in a rural outside area.

\section{Study Design}

A cross-sectional study design was utilized. Following Human Subject approval, each center staff contacted school officials to solicit permission to distribute the survey before the school visit. When a school visits a center, it typically brings all of the students in a particular grade level on buses for the field trip. In order to address intra-center variability, we included no more than two classes from the same grade and no more than two classes from the same school in the data for the study. Classes from 15 schools participated during the survey period. Data was collected using computer systems (Audience Response System or Computer Polling System) that combine data from multiple participants responding via individual, remote, electronic keypads. The keypads look like tiny television remotes and allow students to select a number or letter as their response to the questions as they appear on a large screen at the front of the room, while a staff person simultaneously reads the question. Students are given a minute or two to respond, or change their answer, before the answers are recorded and summarized. Participation was voluntary, and all responses were kept anonymous. Students whose parents did not want them to participate were excluded.

\section{Measures}

The survey and script were created and revised by the research team based on literature review, pilot studies and qualitative feedback from two classes at one health education center. The data collection method included a short questionnaire with close-ended questions. It included two demographic questions (gender and age), three questions regarding self-reported eating behavior (servings of fruits and vegetables consumed and breakfast eating), one question regarding how often they personally try to eat healthy, one question regarding who typically chooses the food they eat, and two questions regarding communication received for healthy eating (where do you get information... and how often does your family talk about... eating healthy). Possible answers for all of these items can be seen in Table 1.

\section{Analysis}

Proportions for the demographic item and each eating behavior question were calculated. Through chi-square tests, differences in outcomes by age were calculated. Multivariate logistic regression was then used to examine the association between predictor variables (gender, age, who chooses food, family discussions, and preferred sources of nutrition information) with 
each outcome variable separately $(3+$ servings of vegetables/day, $2+$ servings of fruit/day, 5+ fruits and vegetables/day, and eating breakfast).

\section{Results}

\section{Descriptive statistics}

Approximately one-third of the respondents reported no vegetable consumption the previous day; only $26 \%$ met the HP 2010 objectives of three or more servings of vegetables per day. Approximately $38 \%$ of the study participants met the Five-A-Day recommendations for fruits and vegetables. Regarding breakfast consumption, nearly two-thirds of the early adolescents reported eating breakfast at home. One in five (19\%) early adolescents usually skipped breakfast. Most early adolescents (58\%)

\section{Table 1}

Survey Responses by Age ( $\mathrm{n}=959)$

\begin{tabular}{|c|c|c|c|c|c|c|c|}
\hline & \multirow[t]{2}{*}{ All } & \multicolumn{4}{|c|}{ Age } & \multirow[b]{2}{*}{$X^{2}$} & \multirow[b]{2}{*}{$\mathrm{df}$} \\
\hline & & 9 & 10 & 11 & $12 / 13$ & & \\
\hline Yesterday, how many times did you eat a vegetable? & & & & & & 6.63 & 12 \\
\hline None & $33 \%$ & $35 \%$ & $32 \%$ & $31 \%$ & $35 \%$ & & \\
\hline One & $25 \%$ & $22 \%$ & $27 \%$ & $26 \%$ & $22 \%$ & & \\
\hline Two & $16 \%$ & $15 \%$ & $15 \%$ & $18 \%$ & $16 \%$ & & \\
\hline Three or more & $26 \%$ & $28 \%$ & $26 \%$ & $25 \%$ & $27 \%$ & & \\
\hline $\begin{array}{l}\text { Yesterday, how many times did you eat fruit or drink } \\
100 \% \text { fruit juice? }\end{array}$ & & & & & & 16.52 & 12 \\
\hline None & $20 \%$ & $22 \%$ & $19 \%$ & $18 \%$ & $24 \%$ & & \\
\hline One & $24 \%$ & $25 \%$ & $23 \%$ & $25 \%$ & $21 \%$ & & \\
\hline Two & $17 \%$ & $19 \%$ & $20 \%$ & $16 \%$ & $14 \%$ & & \\
\hline Three or more & $39 \%$ & $34 \%$ & $38 \%$ & $41 \%$ & $41 \%$ & & \\
\hline I try to eat healthy: & & & & & & $40.65 * *$ & 12 \\
\hline All the time & $26 \%$ & $38 \%$ & $26 \%$ & $21 \%$ & $10 \%$ & & \\
\hline Most of the time & $35 \%$ & $29 \%$ & $37 \%$ & $39 \%$ & $34 \%$ & & \\
\hline Sometimes & $24 \%$ & $20 \%$ & $22 \%$ & $25 \%$ & $36 \%$ & & \\
\hline Once in a while & $10 \%$ & $8 \%$ & $10 \%$ & $10 \%$ & $14 \%$ & & \\
\hline Never & $5 \%$ & $5 \%$ & $5 \%$ & $5 \%$ & $6 \%$ & & \\
\hline What do you usually do for breakfast? & & & & & & $50.29 * *$ & 12 \\
\hline I usually do not eat breakfast & $19 \%$ & $12 \%$ & $18 \%$ & $20 \%$ & $31 \%$ & & \\
\hline I eat breakfast at home & $65 \%$ & $80 \%$ & $63 \%$ & $66 \%$ & $49 \%$ & & \\
\hline I eat breakfast at school & $9 \%$ & $4 \%$ & $12 \%$ & $8 \%$ & $9 \%$ & & \\
\hline Something else & $7 \%$ & $4 \%$ & $7 \%$ & $6 \%$ & $11 \%$ & & \\
\hline $\begin{array}{l}\text { Where do you get most of the information about } \\
\text { eating healthy? }\end{array}$ & & & & & & $35.67 * *$ & 12 \\
\hline A family member & $36 \%$ & $26 \%$ & $41 \%$ & $40 \%$ & $37 \%$ & & \\
\hline School & $28 \%$ & $37 \%$ & $19 \%$ & $27 \%$ & $34 \%$ & & \\
\hline A nurse or doctor & $19 \%$ & $22 \%$ & $21 \%$ & $17 \%$ & $10 \%$ & & \\
\hline Television or the internet & $7 \%$ & $6 \%$ & $6 \%$ & $7 \%$ & $8 \%$ & & \\
\hline Somewhere else & $10 \%$ & $9 \%$ & $13 \%$ & $9 \%$ & $11 \%$ & & \\
\hline $\begin{array}{l}\text { How often does your family talk about eating } \\
\text { healthy? }\end{array}$ & & & & & & $29.96 * *$ & 9 \\
\hline Never & $15 \%$ & $17 \%$ & $15 \%$ & $10 \%$ & $19 \%$ & & \\
\hline Once in a while, but not every month & $39 \%$ & $46 \%$ & $36 \%$ & $35 \%$ & $39 \%$ & & \\
\hline Every month, but not every week & $17 \%$ & $15 \%$ & $13 \%$ & $24 \%$ & $18 \%$ & & \\
\hline Every week & $29 \%$ & $22 \%$ & $36 \%$ & $31 \%$ & $24 \%$ & & \\
\hline Most of the time, who chooses the food you eat? & & & & & & 11.70 & 9 \\
\hline My father & $6 \%$ & $9 \%$ & $4 \%$ & $6 \%$ & $4 \%$ & & \\
\hline My mother & $31 \%$ & $34 \%$ & $32 \%$ & $33 \%$ & $26 \%$ & & \\
\hline I do & $58 \%$ & $54 \%$ & $59 \%$ & $56 \%$ & $64 \%$ & & \\
\hline Someone else & $5 \%$ & $3 \%$ & $5 \%$ & $5 \%$ & $6 \%$ & & \\
\hline
\end{tabular}

Note: $*=\mathrm{p}<0.05, * *=\mathrm{p}<0.01$ 
reported choosing the food they eat most of the time. Fifty-four percent of the early adolescents

reported never or only once-in-a-while having familial discussions about healthy eating. Early adolescents were more likely to receive healthy eating information from family (36\%), and school (28\%). (See Table 1)

\section{Hypothesis Testing}

Logistic regression was used to examine six research questions. Results for each question are shown below. (See Table 2)

1) Adolescents' perceived control over food choices was not associated with fruit and vegetable consumption.

2) Early adolescents who reported more frequent family communication regarding healthy eating were more likely to report eating two or more vegetables per day $(A O R=1.4, p<.05)$, three or more fruits per day $(A O R=1.6, p<.05)$, and five or more vegetables and fruits per day $(A O R=1.9$, $p<.05)$ than early adolescents who reported less frequent family communication regarding healthy eating.

3) Early adolescents did not vary according to their preferred source of nutrition information (e.g., family member, school, nurse or doctor, TV/internet or elsewhere) on their fruit and vegetable consumption. The most preferred source of nutrition information was parents $(36 \%)$.

4) Early adolescents who reported choosing their own food most of the time did not significantly differ on breakfast consumption compared to those who reported that their parents chose food for them most of the time. However younger age was associated with more frequent breakfast consumption.

5) Early adolescents who reported more frequent family communication regarding healthy eating were more likely to report usually eating breakfast $(A O R=1.8, \quad p<.05)$ than early adolescents who reported less frequent family communication regarding healthy eating.
6) Breakfast consumption frequency did not vary according to early adolescents' preferred source of nutrition information (e.g., family member, school, nurse or doctor, TV/internet or elsewhere) was not related to breakfast consumption.

\section{Discussion}

The consumption of fruits and vegetables among early adolescents in this study (ages 9-13) was well below the recommended level of three to five servings a day. About one-third of the early adolescents reported eating no vegetables in the previous day. Early adolescents whose parents discussed with them the benefits of eating fruits and vegetables were more likely to consume the recommended amount of fruits and vegetables than those whose parents did not talk about healthy eating with their children. Timlin, Pereira, Story, and Neumark-Sztainer (2008) found that breakfast eating declines through adolescence, which is supported by this study's findings. In this study, skipping breakfast increased with age, increasing from $12 \%$ of 9 year olds to nearly one-third of 12 and 13 year olds. Additionally, early adolescents whose parents did not talk to them about nutrition were more likely to skip breakfast. While $37 \%$ of the students at participating schools qualified for free or reduced school lunch, only $9 \%$ of respondents ate breakfast at school; increasing school breakfast participation may be an effective dietary intervention for students without caregivers who encourage healthy eating and tend to skip breakfast.

Parents and caregivers discussing healthy eating with their children was associated with early adolescents' healthy eating behaviors regardless of reported control over food choices (i.e., if a parent or early adolescent usually made food choices). This finding indicates that adolescents maintain food habits formed in the home even when eating in different contexts, such as the school cafeteria. Despite numerous media outlets and platforms that compete for the attention of young consumers, parent-child communication is still a key influencing factor of early adolescent healthy eating behavior. 
Table 2

Multivariate logistic regression of outcome variables $(n=959)$

Adjusted odds ratios

\begin{tabular}{|c|c|c|c|c|c|}
\hline & & $\begin{array}{c}3+\text { Veggies } \\
\text { Yesterday }\end{array}$ & $\begin{array}{l}2+\text { Fruit } \\
\text { Yesterday }\end{array}$ & $\begin{array}{c}5+\text { Veggies and/ } \\
\text { or Fruit } \\
\text { Yesterday }\end{array}$ & $\begin{array}{c}\text { Usually Eat } \\
\text { Breakfast }\end{array}$ \\
\hline Gender & $\begin{array}{l}\text { Girl } \\
\text { Boy }\end{array}$ & $\begin{array}{c}1.15 \\
\text { Reference } \\
\text { group }\end{array}$ & $\begin{array}{l}0.97 \\
\text { Reference } \\
\text { group }\end{array}$ & $\begin{array}{l}1.22 \\
\text { Reference } \\
\text { group }\end{array}$ & $\begin{array}{c}0.86 \\
\text { Reference } \\
\text { Group }\end{array}$ \\
\hline $\begin{array}{l}\text { Age group } \\
\text { (years) }\end{array}$ & $\begin{array}{l}12 / 13 \\
11 \\
10 \\
9 \text { years }\end{array}$ & $\begin{array}{c}0.79 \\
0.76 \\
0.87 \\
\text { Reference }\end{array}$ & $\begin{array}{c}1.09 \\
1.08 \\
1.19 \\
\text { Reference }\end{array}$ & $\begin{array}{c}1.42 \\
1.07 \\
1.03 \\
\text { Reference }\end{array}$ & $\begin{array}{c}0.25^{*} \\
0.36^{*} \\
0.45^{*} \\
\text { Reference }\end{array}$ \\
\hline $\begin{array}{l}\text { Who usually } \\
\text { chooses } \\
\text { food }\end{array}$ & $\begin{array}{l}\text { Child } \\
\text { Parent }\end{array}$ & $\begin{array}{c}0.90 \\
\text { Reference }\end{array}$ & $\begin{array}{c}0.94 \\
\text { Reference }\end{array}$ & $\begin{array}{l}1.05 \\
\text { Reference }\end{array}$ & $\begin{array}{c}1.32 \\
\text { Reference }\end{array}$ \\
\hline $\begin{array}{l}\text { Family } \\
\text { Discussion } \\
\text { about eating } \\
\text { healthy }\end{array}$ & $\begin{array}{l}\text { At least monthly } \\
\text { Never/ } \\
\text { once- in- a -while }\end{array}$ & $\begin{array}{c}1.45^{*} \\
\text { Reference }\end{array}$ & $\begin{array}{c}2.38^{*} \\
\text { Reference }\end{array}$ & $\begin{array}{c}1.93^{*} \\
\text { Reference }\end{array}$ & $\begin{array}{c}1.99 * \\
\text { Reference }\end{array}$ \\
\hline \multirow[t]{4}{*}{$\begin{array}{l}\text { Where to get } \\
\text { information }\end{array}$} & $\begin{array}{l}\text { School } \\
\text { Doctor or nurse }\end{array}$ & $\begin{array}{l}0.63 \\
0.63\end{array}$ & $\begin{array}{l}0.83 \\
0.95\end{array}$ & $\begin{array}{l}0.62 \\
0.80\end{array}$ & $\begin{array}{l}0.80 \\
0.97\end{array}$ \\
\hline & TV/web & 0.82 & 0.50 & 0.85 & 1.06 \\
\hline & Other sources & 0.79 & 0.70 & 0.99 & 0.70 \\
\hline & Family & Reference & Reference & Reference & Reference \\
\hline
\end{tabular}

Note: $*=$ odds ratio statistically significant at $\mathrm{p}<0.05$

Parents/caregivers should be encouraged to talk to their children about healthy food choices.

\section{Limitations and Recommendations}

Participants in this study were not randomly selected; however, school-level demographics approximated national proportions. Participants were limited to selecting one preferred answer from a finite list of choices, which potentially decreases response variability. The research could be expanded to include additional quantitative or qualitative survey questions as well as observational assessments to better evaluate the type, quality, and quantity of nutrition information that is being exchanged between parents/caregivers and early adolescentaged children. For example, are early adolescent simply passive listeners or do they actively seek information about healthy eating? Further, what is the nature of these family discussions? Under circumstances do they occur? Do they occur only at meal times? Are they part of a family tradition? Do they occur in naturally conversation or are they planned by parents? 


\section{Conclusion}

This study reinforced the important role parents and other caregivers play in the development of healthy eating patterns. Early adolescents depend on their parents or caregivers not only for food availability, but also for healthy eating knowledge, attitudes and behaviors. Although healthy eating declines with age, early adolescents whose families have and reinforce healthy eating patterns are more likely to maintain those healthy patterns. In addition to traditional classroom instructional practices, health educators should develop creative ways to involve parents and caregivers in nutritionrelated programs and school policies.

\title{
References
}

Benton, D. (2004). Role of parents in the determination of the food preferences of children and the development of obesity. International Journal of Obesity \& Related Metabolic Disorders, 28, 858-869.

Gleason, P.M. \& Dodd, A.H. (2009). School breakfast program but not school lunch program participation is associated with lower body mass index. Journal of the American Dietetic Association, 109, S118-S128.

Healthy People 2010. (2000). Summary of objectives. Retrieved December 2, 2009, from http://www.healthypeople.gov/document/html/volume2/19nutrition.htm\#_Toc49038312

Larson, N.I., Neumark-Sztainer, D., Hannan, P.J., \& Story, M. (2007). Trends in adolescent fruit and vegetable consumption, 1999-2004: Project EAT. American Journal of Preventive Medicine, 32, 147-150.

Nystrom, A.A., Schmitz, K.H., Perry, C.L., Lytle, L.A., \& Neumark-Sztainer, D. (2005). The relationship of weight-related perceptions, goals, and behaviors with fruit and vegetable consumption in young adolescents. Preventive medicine, 40, 203-208.

O'dea, J.A. (2004). Children and adolescent's eating habits and attitudes: Preliminary findings from the National Nutrition and Physical activity study. Nutri Date, 15, 1-4.

Rampersaud G.C., Pereira M.A., Girard B.L., Adams J, Metzl J.D. (2005). Breakfast Habits, Nutritional Status, Body Weight, and Academic Performance in Children and Adolescents Journal of the American Dietetic Association, 105(5), 743-760.

Roseman, M.G., Yeung, W.K., \& Nickelsen, J. (2007). Examination of weight status and dietary behaviors of middle school students in Kentucky. Journal of the American Dietetic Association, 107, 1139-1145.

Timlin, M.T., Pereira, M.A., Story, M., \& Neumark-Sztainer, D. (2008). Breakfast eating and weight change in a 5 year prospective analysis of adolescents: Project EAT. Pediatrics, 121, e638-e645.

Woodruff, S.J. and Hanning, R.M. (2008). A review of family meal influence on adolescent's dietary intake. Canadian Journal of Dietetic Practice and Research, 69, 14-21.

\author{
$\underline{\text { Author Information }}$ \\ *Stephen L Brown, PhD \\ Associate Professor \\ Public Health Education \\ Southern Illinois University \\ Mailcode 4632 \\ Carbondale, IL 62901 \\ Phone: (618)453-1863 \\ Fax: (618)453-1829 \\ Email: slbrown@siu.edu
}


Brown, S.L., Teufel,J., Gautam,Y.R., Norrick, C. \& Birch, D. / Californian Journal of Health Promotion 2012, Volume 10, Special Issue: Obesity Prevention an d Intervention, 64-70

\author{
James Teufel, MPH, PhD \\ National Health Director \\ OASIS Institute \\ Yuba R. Gautam, MD, PhDc \\ Public Health Education \\ Southern Illinois University \\ Christie Norrick, MSW \\ Graduate Student \\ Brown School \\ Washington University \\ David Birch. PhD \\ Department Chair and Professor \\ Health Science \\ University of Alabama \\ * corresponding author
}

